\title{
A multicentre study of how goal-setting is practised during inpatient stroke rehabilitation
}

DOI:

$10.1177 / 0269215517719485$

\section{Document Version}

Accepted author manuscript

Link to publication record in Manchester Research Explorer

\section{Citation for published version (APA):}

Plant, S., \& Tyson, S. (2017). A multicentre study of how goal-setting is practised during inpatient stroke rehabilitation. Clinical Rehabilitation. https://doi.org/10.1177/0269215517719485

\section{Published in:}

Clinical Rehabilitation

\section{Citing this paper}

Please note that where the full-text provided on Manchester Research Explorer is the Author Accepted Manuscript or Proof version this may differ from the final Published version. If citing, it is advised that you check and use the publisher's definitive version.

\section{General rights}

Copyright and moral rights for the publications made accessible in the Research Explorer are retained by the authors and/or other copyright owners and it is a condition of accessing publications that users recognise and abide by the legal requirements associated with these rights.

\section{Takedown policy}

If you believe that this document breaches copyright please refer to the University of Manchester's Takedown Procedures [http://man.ac.uk/04Y6Bo] or contact uml.scholarlycommunications@manchester.ac.uk providing relevant details, so we can investigate your claim.

\section{OPEN ACCESS}




\title{
A multi-centre study of how goalsetting is practised during inpatient stroke rehabilitation
}

\section{Cover title: How is goal-setting practiced during in-patient stroke rehabilitation?}

\author{
Authors: Sarah F Tyson ${ }^{1,2}$, Sarah Plant ${ }^{1,2}$ \\ ${ }^{1}$ Stroke Research Centre, University of Manchester, Manchester Academic Health Science \\ Centre; ${ }^{2}$ Division of Nursing, Midwifery and Social Work, University of Manchester
}

Corresponding Author: Sarah F Tyson, Division of Nursing Midwifery and Social Work, Jean McFarlane Building University of Manchester, Oxford Rd, Manchester M13 9PU. Tel 44(0)7810562538. Email sarah.tyson@manchester.ac.uk

Key Words: stroke, rehabilitation, goal-setting

\section{Abstract}

Objective: To describe goal-setting during in-patient stroke rehabilitation.

Design: There were two stages: An electronic questionnaire for multi-disciplinary teams and an analysis of goal-setting documentation for rehabilitation patients.

Setting: Five in-patient stroke units

Participants: Staff involved in goal-setting and patients undergoing stroke rehabilitation in Results: 13 therapists and 49 patients were recruited. 351 documented goals were examined. All units used therapist-led goal-setting (60\% of goals were set by therapists). $72 \%$ of goals were patient focussed but patients and families had little involvement. Goals focussed on basic mobility and activities of daily living ( $50 \%$ and $\sim 25 \%$ of goals respectively). Only $41 \%$ of documented goals met the SMART criteria. Review of progress was limited. $48 \%$ of goals were never reviewed and $24 \%$ of the remainder were merely marked as "ongoing' without a date or plan for completion. New goals and actions were 
How is goal-setting practiced during stroke rehabilitation?

often documented without any connection to previous goals. Integration between goals and treatment/action plans was mixed. In two units, goals were unconnected to a treatment or action plan, but for the remainder it was $90-100 \%$. However that connection was generally vague and amounted to suggestions of the type of treatment modality that staff might employ.

Conclusions: Goal-setting during in-patient stroke rehabilitation is therapist-led but discussed with the multi-disciplinary team. Therapists mainly identified patient-focussed mobility and activities of daily living goals. Monitoring progress and revising goals were often uncompleted. Links between goals and treatment, action plans and progress were patchy. 
How is goal-setting practiced during stroke rehabilitation?

\section{Introduction}

Goal-setting is a process by which a behavioural target for the user/patient is identified and agreed by a patient, therapist or team and is worked towards over a specified period of time [1]. It is considered an integral part of stroke rehabilitation as it is thought to improve patient well-being and engagement with rehabilitation, while enhancing multi-disciplinary team communication and collaboration [1-3]. It is thought that this occurs by focusing attention and effort towards patients' problems and needs [4]. Consequently goal-setting is recommended in clinical guidance for stroke rehabilitation $[5,6]$ stating that goals should use the 'SMART' format (that is be specific and meaningful for the patient, assessable, realistic (i.e. challenging but achievable) and time limited [7]. Goals should also focus on activity and participation, include both short-term and long-term elements, be used to inform treatment and be reviewed regularly. It is also recommended that stroke survivors and their family should be involved in the process and patients should receive copies of their goals. Lastly, patients should be given help to understand the nature and process of goal-setting, and to define and articulate their personal goals $[1,5]$.

Despite the widespread guidance recommending goal-setting, the evidence base to support it is weak. Several systematic reviews [1-3] have found the evidence to be of low methodological quality and studies were too heterogenic to draw firm conclusions about efficacy, effectiveness, feasibility or acceptability. Furthermore barriers to goal-setting have been consistently reported by patients, families and professionals [8], particularly during acute/ sub-acute and inpatient stroke rehabilitation. Differences in staff and patients' perspectives of goal-setting and rehabilitation; limited patient participation, professional skill and resources, and conflicting priorities have been described by both patients and professionals to contribute to difficulty using goal-setting methods [8]. Several methods of goal-setting during stroke rehabilitation have been proposed but no gold standard has emerged $[1,2,9-18]$. It is thus unsurprising that implementation of goal-setting in clinical practice is considered highly variable $[10,19]$.The need for further research into how goalsetting is implemented has been highlighted [3] as, at present, little is known about how goal-setting is used in routine practice, or how the practice standards highlighted above are (or are not) achieved [10]. 
How is goal-setting practiced during stroke rehabilitation?

The aim of this Phase I study was to explore how goal-setting is practiced during in-patient stroke rehabilitation. Specifically our objectives were to explore: the nature and focus of the goals set; who was involved; how goals are set, monitored, progressed and integrated with other aspects of rehabilitation processes.

\section{Method}

A mixed methods approach was used; an online survey of stroke rehabilitation teams regarding their goal-setting practice and views plus documentary analysis of the clinical records related to goal-setting in five UK National Health Service (NHS) in-patient stroke services. Favourable ethical approval was obtained by the Greater Manchester South Research Ethics Committee and the University of Manchester.

\section{Staff survey}

Qualified professionals in the hospital stroke service of participating hospitals who were involved in goal-setting were recruited. As we wished to recruit a broad, representative sample, there were no further selection criteria. The first author (SP) contacted a lead person in each in-patient stroke team who then contacted members of the team to ascertain whether they were interested in participating and agreed for their contact details to be forwarded to the research team. Once contact was established and it was confirmed the clinician met the inclusion criteria, a participant information sheet and a link to the online questionnaire (Appendix 1) was sent by email. The clinician was asked to complete a simple consent paragraph at the start of the questionnaire.

The questionnaire was specifically developed for the project to address the research objectives (detailed above). The content and format was based on the literature and the authors' experience using closed and open questions and Likert scales. The questionnaire was piloted with five stroke therapists (in a range of job grades) who were independent of the study and participating units. They were asked to comment on the comprehensiveness of the questions, format and ease of completion. Feedback highlighted a few typographical errors, areas for clarification and suggestions to enhance usability, which were amended before circulation to participants. 
How is goal-setting practiced during stroke rehabilitation?

\section{Analysis of Clinical Notes}

Adult stroke patients who were receiving rehabilitation in the participating hospitals and were able to consent (or there was somebody from whom assent could be sought) were recruited. As we wished to recruit a broad representative sample of patients receiving rehabilitation, there were no further recruitment criteria. They were asked to consent to the researcher having access to their clinical notes. They had no further involvement in the study.

Patients who met the inclusion criteria were identified by a member of the stroke team and were approached by the research team or local research practitioner to introduce and explain the study, provide participant information sheets and answer any questions. For those who wished to participate, consent or assent was then obtained and the formal clinical goal-setting documentation accessed for each patient. For patients who had been an in-patient for some time, this included documentation for several weeks, or even months. To ensure anonymity, a blank copy of the goal-setting proforma used at the participating unit was obtained and anonymised information from the clinical documentation copied on to it. This was completed for all relevant documentation for each patient. The participants' Barthel Index [20] (a routinely recorded measure of independence in the activities of daily living) score on admission and time since stroke were also recorded.

From the notes, the following data were recorded:

- the nature of the goal mapped against the domains of the international Classification of Functioning, Disability and Health (ICF) [21]

- the focus of the goal - who (eg patient, family, staff) and what the goal involved (eg treatment to be received; action planned; referral made, equipment ordered)

- who was involved in setting the goals

- the process of goal-setting - how goals were set

- whether the goal set was 'SMART' (Specific, Measurable, Achievable, Timely)

- how goals were monitored and reviewed including timescale for achievement and whether the goal was achieved

- whether or how the goals were integrated with any other rehabilitation processes 
How is goal-setting practiced during stroke rehabilitation?

\section{Results}

\section{Staff Questionnaire}

Thirteen stroke clinicians were recruited from participating hospitals in Greater Manchester, of whom six were physiotherapists, five were occupational therapists, one was a speech and language therapist and one was a dietician. Five (39\%) worked in an acute stroke unit; two (15\%) in a rehabilitation unit and six worked in a combined acute and rehabilitation unit (46\%). Most were NHS band 6 or 7 (specialist or highly specialist therapist respectively, both $n=5,38.5 \%)$. Mean length of clinical experience was $15.6(S D=10.6)$ years and the mean length of experience in stroke rehabilitation was $10.2(S D=9.6)$ years. Most $(n=10,77 \%)$ had been using goal-setting for over 3 years.

All respondents used goal setting, for all patients. Most reported that they set goals on the day of assessment $(n=7,54 \%)$ with the others setting goals within the first week of referral/admission. They reported that they involved others in goal-setting at multiple levels. Five set goals on their own; four also included other members of their profession; ten (77\%) reported involving the patient and families and 10 also involved the multi-disciplinary team.

All used proforma to document the goal-setting. One only recorded the goals in their uniprofessional notes, five just used multi-disciplinary notes and 5 used both. Those who set goals on an uni-professionally basis did so because they felt the goals were specific to their profession.

The time spent goal-setting was highly varied; from 30 minutes daily to one hour weekly. Most included goal-setting in their weekly multi-disciplinary (care planning) meeting which typically lasted one hour. Respondents reported that they used the goals to inform discussion in meetings and decision-making either explicitly $(n=10)$ and implicitly $(n=6)$. Most were happy with their goal-setting practice. Five felt it was fully effective; five reported it was quite effective and only one felt it was only slightly effective. They perceived the benefits of goal-setting to be that it supported care planning (be that assessment, treatment, or action plans or discharge planning) and progress monitoring; that it motivated patients and staff by giving a focus to treatment and promoting a patient- 
How is goal-setting practiced during stroke rehabilitation?

centred approach. They also felt it facilitated multi-disciplinary collaboration and understanding of each other's roles. The reported barriers to goal-setting were lack of time $(n=4)$; lack of engagement by some team members $(n=3)$ and patient's stroke-related limitations $(n=2)$. Greater involvement by patients and families was the main way they felt goal-setting could be improved.

None used a specific goal-setting tool such as Goal Attainment Scale (GAS) or the Canadian Occupational Performance Measure. Three reported that they, or the team had developed their own method and two used 'SMART' criteria. Eight (62\%) stated that standardized outcome measures were used during goal-setting to define goals $(n=3)$; monitor progress $(n=6)$ and goal achievement $(n=5)$ or to set new goals $(n=3)$. However, clinical judgement was the most frequently used method to ascertain whether a goal had been achieved. Most $(85 \% \mathrm{n}=11)$ perceived that they included the patient and/or their family by discussing goals and families during assessment or treatment sessions $(n=10)$, telling the patients about the goals that that had been set for them $(n=6)$, giving patients a written copy of the goals $(n=1)$ or both $(n=3)$. The most common reasons for not involving the patient or family were patients' communication difficulties; lack of time; concerns about families having unrealistic expectations or difficulty arranging to meet them.

Respondents perceived that they reviewed the goals regularly; daily or after each treatment session ( $n=8,60 \%)$ and/or weekly $(n=7,54 \%)$. All stated that goals were reviewed and progressed within multi-disciplinary team meetings although seven (54\%) reported that they set the goals and then informed the team at the meeting. Four reported that they revised goals with the patients during treatment sessions.

\section{Analysis of Clinical Notes}

Forty-nine patients gave access to their clinical notes from whom 351 goal-setting records were analysed. The mean time since stroke was $37(S D=44.4)$ days and the mean Barthel Index score was $7.8(S D=6.3)$. The mean number of goals set per patient was $7(S D=8.4$; median 5; mode 3). Two outliers were identified, who had 54 and 34 goals, both of whom had been an in-patient in the same stroke unit for over one year. Without these 
How is goal-setting practiced during stroke rehabilitation?

participants, the mean number of goals was $5.6(S D=2.9)$; median and mode were unchanged.

\section{Nature and focus of the goals}

The focus of the documented goals was predominantly disability-related, particularly regarding mobility, transfers and balance which accounted for almost $50 \%$ of goals (Table 1 ). Basic activities of daily living (washing and dressing, toileting; eating and drinking and making a simple meal) accounted for a quarter of goals. Cognition and vision featured 14 (5.3\%) and 13 (4.9\%) times respectively. Communication featured in only 7 (2.7\%) goals. Mood and the upper limb (grasping) featured only once each. Pain, swallowing, sleep, fatigue, skin integrity, self-medication and continence did not feature at all.

Most goals involved the patient ( $n=251,72 \%$ ), however nearly a quarter of goals were specifically for staff $(n=96,27 \%)$ and four involved the family. This data was skewed by one unit in which only $32 \%$ of goals involved the patient. In the other units $82 \%-95 \%$ were patient focused. Most of the goals $(n=263,75 \%)$ concerned treatment or action plans for patients, but this was again skewed by one unit were over $50 \%$ focused on staff actions (such as ordering equipment, undertaking assessments, attending or planning meetings with families or other staff, or organising home visits).

\section{Who was involved in goal-setting?}

The meeting in which goals were discussed involved the multi-disciplinary team; therapists, nurses and doctors. Some units also involved a stroke co-ordinator; social worker or dietician. At all units the problems and goals were identified and defined by the staff, mainly the therapists. $60 \%$ of goals were set by the therapists; 109 (31\%) goals by an occupational therapist; 95 (27\%) by a physiotherapist and 7 (2\%) by a speech therapist.

One unit involved patients insofar as they routinely documented whether the goals were shared with patients. Overall only $40(11 \%)$ of the documented goals were shared with the patients; all from the same unit. 
How is goal-setting practiced during stroke rehabilitation?

\section{How were goals set?}

At all units, goal-setting was included in weekly multi-disciplinary team meetings which also covered assessment, monitoring progress and action/treatment plans (further details in Table 2). At one unit, the therapists met beforehand to set goals which were reported to the team meeting. All units except one kept the goal-setting documentation in the patients' multi-disciplinary care plan. Three units also kept separate uni-professional goal-setting notes. None of the participating units used a specific goal-setting method or tool. All units identified the patients' goals in the first meeting, which was typically within the first week after the stroke or admission to the rehabilitation unit, and noted the date the goal was set and achieved (Table 2). Two units phrased the goals in terms of the profession setting them (so they were professionals' goals, rather than the patients'); one used pre-defined areas of function to focus the goals (such as transfers, eating or dressing) and two did not structure the goals. Only one unit specified a time scale for completion of the goal or how completion would be judged/ assessed.

Only $143(41 \%)$ of documented goals met the SMART criteria. The most common reason for this was that a timescale to achieve the goal was not stated. When a timescale was included, this was most frequently one week $(n=109,31 \%)$. There was great variability between units. One unit never used the SMART format, the other units ranged between $21 \%$ and $82 \%$ of documented goals. Observation was the most frequent method used to assess whether a goal had been achieved $(n=21,6 \%)$. Standardised outcomes were stated in $20(6 \%)$ goals.

\section{How goals were monitored and reviewed}

All the goal-setting documentation included an area for the team to review progress by recording whether the goal had been reviewed, and whether it had been achieved or was still 'in progress'. However this was often uncompleted. Forty-eight percent $(n=168)$ of goals were never reviewed. Twenty-four percent of the remainder $(n=85)$ were merely marked as "ongoing' without any date or plan for completion. Poor layout of the documentation and incomplete recording meant it was often unclear which goals were achieved, when a goal 
How is goal-setting practiced during stroke rehabilitation?

was achieved, and how it was progressed. Of the quarter of goals that were reviewed ( $n=95$, $28 \%$ ), only 42 ( $12 \%$ of the total) were progressed with another goal and for 51 (15\%) no further goals were planned. Often new goals and actions were documented each week without any connection to previous goals.

\section{How goals were integrated with other rehabilitation processes}

The documentation at all but one unit had a section of the action/ treatment plans that arose from the team meeting. However the integration between goals and treatment/action planning was mixed. In two units, none of the goals were connected to a treatment or action plan, but for the remainder it was $90-100 \%$. In some units, the staff member responsible for overseeing achievement of the action was routinely identified but more specific detail of the plans was rare. The connection between the goal and treatment plans was usually vague and amounted to suggestions of the type of treatment modality that might staff might employ (See Box 1 for examples) rather than how the modality would be delivered, the dose of treatment or actions involving the patient.

\section{Discussion}

The results show that stroke rehabilitation teams were involved in therapy-led, multidisciplinary goal-setting, which partially met the recommendations in national clinical guidelines [5, 6,]. The SMART format [7] was used but incompletely and inconsistently. Timescales were seldom included and review of progress was patchy. Goals focussed on activity but not participation (although a focus on participation is often inappropriate while an in-patient); short-term goals (typically for one week) were set but not long-term. Goals were discussed in multi-disciplinary care planning meetings (as well as other meetings) and thus informed care plans, but this was often implicit. Explicit integration with other aspects of rehabilitation (treatment, action plans, monitoring progress) was patchy. There was little explicit involvement of patients and their families in goal-setting nor help them understand the process. 
How is goal-setting practiced during stroke rehabilitation?

It is unsurprising that goals set were short term and they focussed on basic mobility and the activities of daily living required for discharge from hospital, given the imperative for speedy discharge from hospital. Nevertheless, it is noteworthy that many aspects of stroke that survivors highlight limits their quality of life [22] featured rarely (communication, cognition, mood, upper limb function) or not at all. Further research is needed to facilitate consideration of these domains during goal-setting and in-patient rehabilitation.

Goal-setting was led by therapists, who identified the problems; defined the goals; assessed whether they had been achieved and decided how they should progress (if this was completed). The lack of involvement of nursing staff in goal-setting, and the lack of goals concerning domains that may be considered the nurses remit (such as skin integrity, selfmedication and continence) was very marked. Further work is needed to develop goalsetting methods that more comprehensively involve all members of the multi-disciplinary team. This may go some way to facilitate a more holistic consideration of patients' difficulties, beyond basic mobility and activities of daily living.

The therapists perceived that they involved patients and families in goal-setting during assessment and treatment sessions, however there was little evidence of this in the documentation. Generally the extent of stroke survivors and their family's involvement was that they were either told, or given a written copy of their goals. Patient involvement is a central tenet of goal-setting, and much of the literature regarding goal-setting focusses on the extent to which patients are involved. It consistently indicates that goal-setting during in-patient stroke rehabilitation rarely, if ever, involves patients and could rarely be considered truly patient-centred [7]. This is because both professionals and patients feel infeasible, and to some extent unacceptable, for many at this stage in the patients' recovery [7]. At this stage, the patients' focus is on "getting back to normal" and they may not feel ready to negotiate this, nor work in the short-term, which is the professionals' focus, given the pressure to expedite discharge $[7,12,22,23]$. They also do not have the knowledge or experience to know what recovery is feasible and expect the professionals to use their expertise to lead them [7, 23]. The limitations imposed by patients' stroke-related difficulties have also been repeatedly raised as a barrier to patient involvement in goalsetting $[6,7]$, which are reflected in the results of the current study. 
How is goal-setting practiced during stroke rehabilitation?

This body of evidence questions the assumption that goal-setting should be patient-led at all stages of stroke recovery. Extensive evidence from professionals, patients and their families suggest that a professional-led approach may be most appropriate during acute/sub-acute rehabilitation, especially while an in-patient. The results of the current study suggests that this is what happens. Further work is needed to develop a model of goal-setting which is 'fit for purpose' for both patients and professional during acute/ sub-acute rehabilitation. One of the participating units routinely informed patients of their goals during a discussion and provided a written copy of the goals. This may be as much patient involvement as many patients want or need at this stage of their recovery.

Interestingly, the questionnaire respondents perceived that they involved patients in goal-setting and reviewed goals more frequently than was suggested by the documented goals. Most reported that they reviewed goals daily or at every treatment session, suggesting that goalrelated clinical reasoning and discussions with patients occur implicitly and informally, possibly during treatment sessions but is not captured by the formal documentation. This is supported by observational studies of goal-setting during in-patient stroke physiotherapy [24,25], which suggested that targets of treatment and goals were topics of conversation between patient and therapist, however decision-making was therapist-led with little active involvement from the patient. An alternative explanation is that their answers to the questionnaire focussed on what they felt was the correct answer, rather than their actual practice

Although stroke teams are able to consistently identify and define goals, they found assessing progress, updating goals and linking this to treatment and action plans more challenging. These aspects of goal-setting were the least consistently completed. Most goals were never reviewed or merely recorded as 'in progress' on review. In some units, the goals were set soon after admission and then effectively abandoned while the team focused on staff action plans to achieve discharge. 
How is goal-setting practiced during stroke rehabilitation?

This is clearly an aspect of goal-setting that need further work, especially as goal-setting is considered an important way to demonstrate the effectiveness of rehabilitation [26]. Further research is needed to explore goal-setting's mechanisms of action to ascertain how it's effects (if any) are mediated and thus how links to other rehabilitation processes can be facilitated; the barriers to doing so, and to develop appropriate user-friendly tools. However, the results of the current study suggest some simple actions which could also make these aspects of goal-setting more effective. Clearer documentation may make it simpler to review goals and make progress explicit as might the use of standardised measurement tools and predicted times to achieve the goals [1].

The literature about goal-setting during stroke rehabilitation generally refers to it as a single activity isolated from other rehabilitation processes. However in all the participating sites, it was integrated with reviews of the patients' assessment and progress, and to treatment/ management plans. These processes are clearly inter-linked and integration should be considered a desirable attribute. We found this integration was mixed. Two sites did not formally make any links between the goals and treatment plans. Nevertheless the patients in these units did receive treatment so it possible that links were made implicitly and not formally documented. Making this link explicit may enable treatment to be more focussed on patients' main difficulties and thus be more effective. Alternatively, such explicit documentation may be unnecessary and merely contribute to the professionals' administrative burden. Further research in to how goal-setting could and should integrate with other rehabilitation processes and their mechanisms of action to develop more acceptable, feasible and effective systems is needed [3].

In considering the results of this study, several limitations should be borne in mind. Firstly only five stroke units in one region were involved. Furthermore four had previously participated in a study to develop and standardise multi-disciplinary team meetings (including goal-setting [27]). So generalisability of the results to other units and other health care systems should be treated with caution. However we reviewed several hundred goals for patients with a wide range of abilities in units using different models of stroke service organisation, so we are reasonably confident the results are representative. Secondly, the results of the questionnaire are dependent on participants' perceptions and the case note analysis is dependent on what was 
How is goal-setting practiced during stroke rehabilitation?

documented. As we highlighted above, some important goal-setting activity may be implicit and informal which was not captured in this study. Also the discrepancies between the responses in the staff questionnaire and the findings from the case note analysis suggest that the questionnaire responses may have been subject to social desirability bias. Further research using more probing semi-structured interviews and observations could address these issues.

\section{Clinical Messages}

- Goal-setting is therapist-led, focussing on mobility and daily tasks. Areas such as continence, cognition or mood are rarely considered.

- Patients and families are not involved beyond being informed of goals set.

- Integrating goal-setting with other rehabilitation processes (such as planning treatment and monitoring progress) is poorly completed.

- Goals and actions tend to be used interchangeably. 
How is goal-setting practiced during stroke rehabilitation?

\section{References}

1. Rosewilliam S, Roskell CA, Pandyan AD. A systematic review and synthesis of the quantitative and qualitative evidence behind patient-centred goal setting in stroke rehabilitation. Clinical Rehabilitation. 2011;25(6):501-14.

2. Sugavanam T, Mead G, Bulley C, Donaghy M, van Wijck F. The effects and experiences of goal setting in stroke rehabilitation - a systematic review. Disability And Rehabilitation. 2013;35(3):177-90.

3. Levack WMM, Weatherall M, Hay-Smith EJC, Dean SG, McPherson K, Siegert RJ. Goal setting and strategies to enhance goal pursuit for adults with acquired disability participating in rehabilitation. The Cochrane Library. 2015.

4. Locke EA. Toward a theory of task motivation and incentives. Organizational Behavior and Human Performance. 1968;3(2):157-89.

5. Royal College of Physicians. National Clinical Guideline for Stroke 2016 [Available from: https://www.rcplondon.ac.uk/guidelines-policy/stroke-guidelines.

6. NICE. Stroke rehabilitation: Long-term rehabilitation after stroke 2013 [Available from: https://www.nice.org.uk/guidance/cg162/evidence/cg162-stroke-rehabilitation-fullguideline3.

7. Bovend'eerdt TJH, Botell RE, Wade DT. Writing SMART rehabilitation goals and achieving goal attainment scaling: a practical guide. Clinical Rehabilitation. 2009;23(4):35261.

8. Plant SE, Tyson SF, Kirk S, Parsons J. What are the barriers and facilitators to goalsetting during rehabilitation for stroke and other acquired brain injuries? A systematic review and meta-synthesis. Clinical Rehabilitation. 2016;30(9):921-30. 
How is goal-setting practiced during stroke rehabilitation?

9. Hurn J, Kneebone I, Cropley M. Goal setting as an outcome measure: a systematic review. Clinical Rehabilitation 2006;20(9):756-72.

10. Playford ED, Siegert R, Levack W, Freeman J. Areas of consensus and controversy about goal setting in rehabilitation: a conference report. Clinical Rehabilitation. 2009;23(4):334-44.

11. Leach E, Cornwell P, Fleming J, Haines T. Patient centered goal-setting in a subacute rehabilitation setting. Disability \& Rehabilitation 2010;32(2):159-72.

12. Holliday RC, Cano S, Freeman JA, Playford ED. Should patients participate in clinical decision making? An optimised balance block design controlled study of goal setting in a rehabilitation unit. Journal of Neurology, Neurosurgery and Psychiatry. 2007;78(6):576-80. 13. Scobbie L, McLean D, Dixon D, Duncan E, Wyke S. Implementing a framework for goal setting in community based stroke rehabilitation: a process evaluation. BMC Health Services Research. 2013;13(1):190.

14. Wressle EWA, Oberg B, Henriksson C. The rehabilitation process for the geriatric stroke patient-an exploratory study of goal setting and interventions. Disability and Rehabilitation. 1999;21(2):80-7.

15. Dalton C, Farrell R, De Souza A, Wujanto E, McKenna-Slade A, Thompson S, et al. Patient inclusion in goal setting during early inpatient rehabilitation after acquired brain injury. Clinical Rehabilitation. 2012;26(2):165-73.

16. Stevens A, Beurskens A, Köke A, van der Weijden T. The use of patient-specific measurement instruments in the process of goal-setting: a systematic review of available instruments and their feasibility. Clinical Rehabilitation 2013:23:0269215513490178. 
How is goal-setting practiced during stroke rehabilitation?

17. Barten JA, Pisters MF, Huisman PA, Takken T, Veenhof C. Measurement properties of patient-specific instruments measuring physical function. Journal of Clinical Epidemiology. 2012;65(6):590-601.

18. Playford ED, Dawson L, Limbert V, Smith M, Ward CD, Wells R. Goal-setting in rehabilitation: report of a workshop to explore professionals' perceptions of goal-setting. Clinical Rehabilitation. 2000;14(5):491-6.

19. Laver K, Halbert J, Stewart M, Crotty M. Patient Readiness and Ability to Set Recovery Goals During the First 6 Months After Stroke. Journal of Allied Health. 2010;39(4):149E-54E.

20. Mahoney FI. Functional evaluation:The Barthel Index. Maryland State Medical Journal. 1965;14:61-5.

21. World Health Organisation. International Classification of Functioning, Disability and Health 2016 [Available from: http://apps.who.int/classifications/icfbrowser/.

22. Van De Weyer RC, Ballinger C, Playford ED. Goal setting in neurological rehabilitation: staff perspectives. Disability and Rehabilitation. 2010;32(17):1419-27.

23. Brown M, Levack W, McPherson KM, Dean SG, Reed K, Weatherall M, et al. Survival, momentum, and things that make me "me": patients' perceptions of goal setting after stroke. Disability and Rehabilitation. 2014;36(12):1020-6.

24. Parry RH. Communication during goal-setting in physiotherapy treatment sessions. Clinical rehabilitation 2004:1;18(6):668-82.

25. Talvitie U, Reunanen M. Interaction between physiotherapists and patients in stroke treatment. Physiotherapy 2002: 28;88(2):77-88. 
How is goal-setting practiced during stroke rehabilitation?

26. Holliday RC, Antoun M, Playford ED. A Survey of Goal-Setting Methods Used in Rehabilitation. Neurorehabilitation and Neural Repair. 2005;19(3):227-31.

27. Tyson SF, Burton L, McGovern A. The impact of a toolkit on use of standardised measurement tools in stroke rehabilitation. Clinical Rehabilitation. 2015;29(9):926-34. 
Table 1. The nature of the documented goals

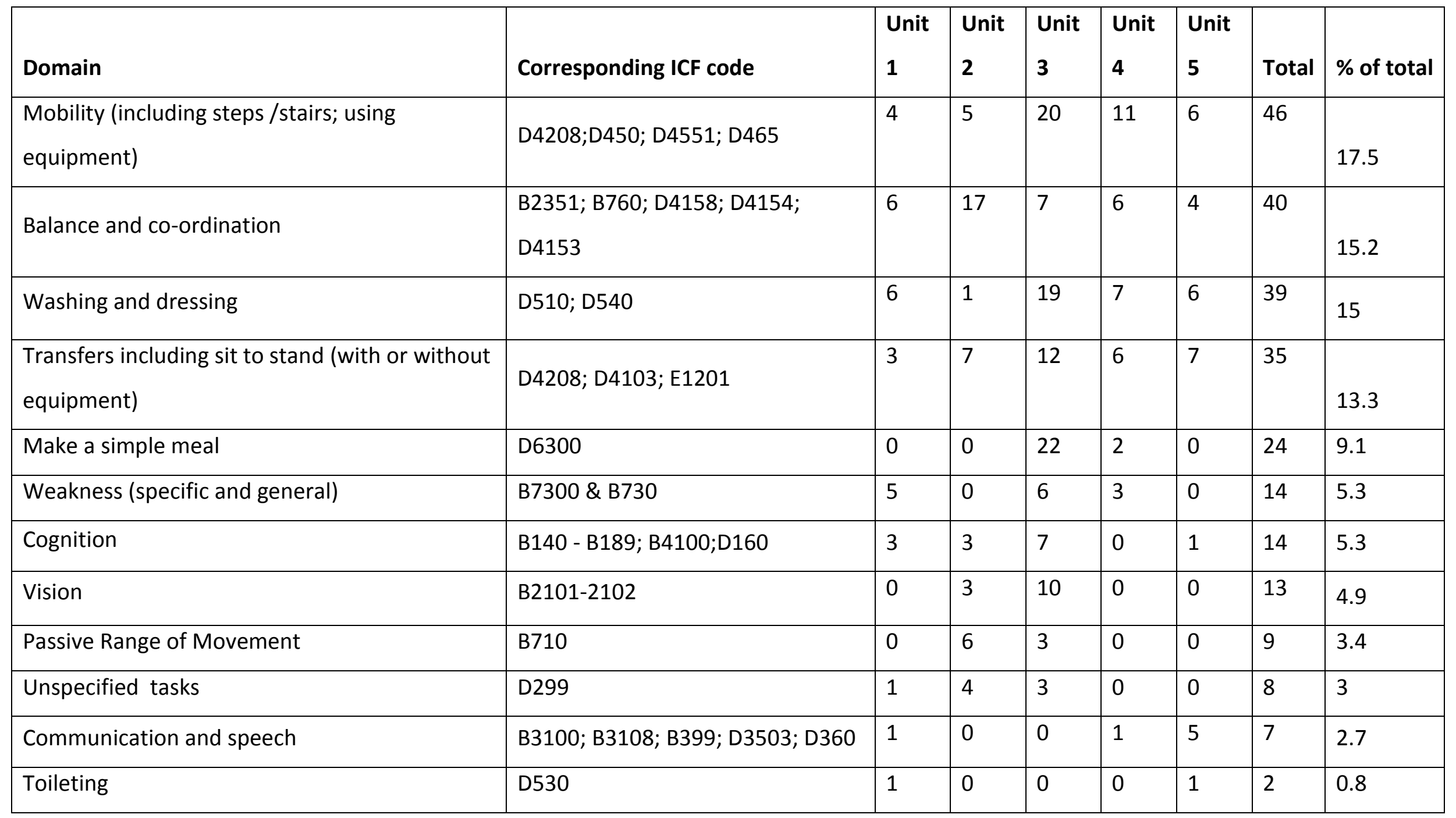


How is goal-setting practiced during stroke rehabilitation?

\begin{tabular}{|c|c|c|c|c|c|c|c|c|}
\hline Self-care (other) & B599 & 1 & 0 & 1 & 0 & 0 & 2 & 0.8 \\
\hline Swallowing, eating and drinking & D550; D559 & 0 & 0 & 2 & 0 & 0 & 2 & 0.8 \\
\hline Perception & B156 & 0 & 0 & 2 & 0 & 0 & 2 & 0.8 \\
\hline Gait pattern & B770 & 0 & 0 & 0 & 1 & 0 & 1 & 0.4 \\
\hline Mood & B152 & 0 & 0 & 1 & 0 & 0 & 1 & 0.4 \\
\hline Respiratory & D440 & 0 & 0 & 1 & 0 & 0 & 1 & 0.4 \\
\hline \multirow[t]{2}{*}{ Grasping } & D4400 & 0 & 1 & 0 & 0 & 0 & 1 & 0.4 \\
\hline & Total & 32 & 47 & 116 & 38 & 30 & 263 & \\
\hline
\end{tabular}


Table 2. How goals are set in the participating units

\begin{tabular}{|c|c|c|c|c|c|}
\hline & Unit 1 & Unit 2 & Unit 3 & Unit 4 & Unit 5 \\
\hline $\begin{array}{l}\text { How often are } \\
\text { goals set/ } \\
\text { reviewed? } \\
\text { Where does } \\
\text { this happen? }\end{array}$ & $\begin{array}{l}\text { Weekly specific goal- } \\
\text { setting meeting involving } \\
\text { therapists }\end{array}$ & $\begin{array}{l}\text { Weekly as part of } \\
\text { MDT meeting (Goal- } \\
\text { setting/ progress/ } \\
\text { planning) }\end{array}$ & $\begin{array}{l}\text { Weekly as part of } \\
\text { MDT meeting (Goal- } \\
\text { setting/ progress/ } \\
\text { planning) }\end{array}$ & $\begin{array}{l}\text { Weekly as part of MDT } \\
\text { meeting (Goal-setting/ } \\
\text { progress/ planning) }\end{array}$ & $\begin{array}{l}\text { Weekly as part } \\
\text { of MDT meeting } \\
\text { (Goal-setting/ } \\
\text { progress/ } \\
\text { planning) }\end{array}$ \\
\hline $\begin{array}{l}\text { Where are } \\
\text { goal-setting } \\
\text { notes kept }\end{array}$ & $\begin{array}{l}\text { Copy of the therapists' } \\
\text { goal sheet included in } \\
\text { patient's care plan } \\
\text { folder. Also profession } \\
\text { specific notes kept } \\
\text { separately }\end{array}$ & $\begin{array}{l}\text { MDT notes in } \\
\text { patients' care plan } \\
\text { folder. Also } \\
\text { profession specific } \\
\text { notes kept } \\
\text { separately }\end{array}$ & $\begin{array}{l}\text { MDT notes in } \\
\text { patients' care plan } \\
\text { folder. Also } \\
\text { profession specific } \\
\text { notes kept separately }\end{array}$ & $\begin{array}{l}\text { MDT notes in patients' care } \\
\text { plan folder. } \\
\text { Also written patient held } \\
\text { documentation }\end{array}$ & $\begin{array}{l}\text { Held in separate } \\
\text { file in therapy } \\
\text { office. }\end{array}$ \\
\hline $\begin{array}{l}\text { How many } \\
\text { forms? }\end{array}$ & $\begin{array}{l}2+2+\text { uni- professional } \\
\text { notes } \\
\text { Weekly MDT goal sheet }\end{array}$ & $\begin{array}{l}\text { 2+ uni- professional } \\
\text { notes } \\
\text { Weekly MDT goal- }\end{array}$ & $\begin{array}{l}\text { 2+ uni- professional } \\
\text { notes } \\
\text { Weekly MDT form }\end{array}$ & $\begin{array}{l}3 \\
\text { Weekly MDT }\end{array}$ & Weekly MDT \\
\hline
\end{tabular}




\begin{tabular}{|c|c|c|c|c|c|}
\hline & $\begin{array}{l}\text { Summary sheet for } \\
\text { problem, goal and } \\
\text { achieved date. } \\
\text { Completed once }\end{array}$ & $\begin{array}{l}\text { setting/ progress } \\
\text { meeting form } \\
\text { MDT action plan } \\
\text { form }\end{array}$ & MDT goal sheet & $\begin{array}{l}\text { problem/goal/Treatment plan } \\
\text { MDT meeting record } \\
\text { MDT action plan }\end{array}$ & $\begin{array}{l}\text { goal summary } \\
\text { MDT input } \\
\text { summary with } \\
\text { goals/ actions }\end{array}$ \\
\hline $\begin{array}{l}\text { Problem } \\
\text { identified }\end{array}$ & Yes & Yes & Yes & Yes & no \\
\hline Goals stated & Yes & Yes & Yes & Yes & Yes \\
\hline Date goal set & Yes & Yes & Yes & Yes & Yes \\
\hline $\begin{array}{l}\text { Predicted time } \\
\text { to complete } \\
\text { the goal }\end{array}$ & No & No & No & Yes & no \\
\hline $\begin{array}{l}\text { Prediction of } \\
\text { discharge date }\end{array}$ & Yes & No & no & Yes & Yes \\
\hline $\begin{array}{l}\text { Prediction of } \\
\text { function at } \\
\text { discharge }\end{array}$ & Yes & No & no & Yes & Yes \\
\hline Prediction of & no & no & no & Yes & no \\
\hline
\end{tabular}


How is goal-setting practiced during stroke rehabilitation?

\begin{tabular}{|l|l|l|l|l|l|}
\hline $\begin{array}{l}\text { discharge } \\
\text { destination }\end{array}$ & & & & \\
\hline $\begin{array}{l}\text { Patient } \\
\text { involvement }\end{array}$ & No & $\begin{array}{l}\text { A section for 'patient } \\
\text { goals' but not } \\
\text { completed }\end{array}$ & $\begin{array}{l}\text { Notes whether the } \\
\text { goal sheet has been } \\
\text { given to patient and } \\
\text { whether agreed with } \\
\text { patient }\end{array}$ & $\begin{array}{l}\text { A section for 'patient goals' } \\
\text { but not completed }\end{array}$ & no \\
\hline SMART & $\begin{array}{l}21 \% \text { of goals met SMART } \\
\text { criteria }\end{array}$ & $\begin{array}{l}\text { 0\% of goals met } \\
\text { SMART criteria }\end{array}$ & $\begin{array}{l}56 \% \text { of goals met } \\
\text { SMART criteria }\end{array}$ & $\begin{array}{l}82 \% \text { of goals met SMART } \\
\text { criteria }\end{array}$ & $\begin{array}{l}55 \% \text { of goals } \\
\text { met SMART } \\
\text { criteria }\end{array}$ \\
\hline
\end{tabular}


How is goal-setting practiced during stroke rehabilitation?

Box 1 - Examples of the treatment and action plans attached to documented goals

"Find appropriate seating and establish sitting out regime" Patient 2 Unit 1

"Sit to stand practice with assistance of 2; encourage weight transfer to left" Patient 2

Unit 2

"For breakfast group" Patient 2 Unit 5

"Kitchen assessment and kitchen tasks" Patient 22 Unit 3

"Washing and dressing practice; errorless learning" Patient 3 Unit 4 